\title{
Improving the regulation of medical cannabis in Canada to better serve pediatric patients
}

\author{
Richard J. Huntsman MD, Lauren E. Kelly PhD, Jane Alcorn DVM PhD, Juan Pablo Appendino MD, \\ Richard E. Bélanger MD, Bruce Crooks MBChB, Yaron Finkelstein MD, Andrea Gilpin PhD MBA, Evan Lewis MD, \\ Catherine Litalien MD, Julia Jacobs MD, Charlotte Moore-Hepburn MD, Timothy Oberlander MD, \\ S. Rod Rassekh MD MHSc, Alexander E. Repetski, Michael J. Rieder MD PhD, Alan Shackelford MD, \\ Hal Siden MD MHSc, Michael Szafron PhD, Geert W. 't Jong MD PhD, Régis Vaillancourt PharmD; \\ for the Cannabinoid Research Initiative of Saskatchewan and the Canadian Childhood Cannabinoid Clinical \\ Trial (C4T) Consortium
}

Cite as: CMAJ 2021 October 18;193:E1596-9. doi: 10.1503/cmaj.202169

C hildren with chronic debilitating illness and pain are increasingly using cannabis for medical purposes, particularly when conventional treatment options have limited benefit or substantial adverse effects. Caregivers are becoming aware of evidence that suggests medical cannabis provides benefit for children with conditions that include drug-resistant epilepsy, cancer pain and autism. ${ }^{1,2}$ At present, children and youth aged 18 years and younger (henceforth referred to as children) access medical cannabis through a framework regulated by Health Canada. In 2018, the Cannabis Act (Bill C-45) created separate medical and recreational streams for purchasing cannabis. ${ }^{3,4}$ Under the law, cannabis treatment for children must be authorized by a physician or nurse practitioner, which provides an opportunity for patient counselling. Strict production and labelling requirements that limit contaminants and create some consistency in cannabinoid concentrations have been instituted, which is good for pediatric cannabis users. ${ }^{5}$ However, requirements for physician authorization are outdated and do not reflect the needs of pediatric patients, and product labelling remains inadequate, as does surveillance for adverse drug reactions in children. Improvements in regulation are needed.

Under current regulations, health care providers must specify the quantity of cannabis authorized for patients in grams of dried cannabis per day. In the latter half of 2018 , cannabis extracts preparations that have been extracted from the leaves and flowers (inflorescence) of Cannabis sativa - accounted for $67 \%$ of cannabis authorized for medical purposes in Canada. ${ }^{6}$ Although no pediatric-specific data exist, clinical experience indicates that extracts, not dried product, are predominantly used for children. If patients use extracts, providers must calculate a dosage conversion to complete the authorization form. The cannabinoid content of the dried cannabis used to produce extracts varies, which complicates the daily dosage conversion from milligrams

\section{Key points}

- Children with chronic debilitating illness and pain are increasingly using cannabis for medical purposes, particularly when conventional treatment options have limited benefit or substantial adverse effects.

- Better processes and regulation are needed in Canada to ensure adequate research into the effectiveness and adverse effects of cannabis products for medical conditions in children and adolescents.

- Refinement of authorization and prescribing processes and mandated adverse effect reporting are needed to enhance patient safety.

- Innovative mechanisms for adequate research funding that is independent of industry influence are required to support research that can strengthen the evidence base on the indications, dosage, efficacy and potential toxicity of medical cannabis for pediatric patients.

of the desired cannabinoid to grams of dried cannabis. Furthermore, different processes for extracting cannabinoids from dried cannabis plant material have the potential to give the resultant extract a distinctive cannabinoid, terpenoid and residual solvent profile. ${ }^{7}$ Individual licensed cannabis producers may have interbatch variability within the same product. Dose calculation is further complicated if the patient uses more than 1 formulation.

Although licensed producers must use validated methods to measure the concentrations of cannabinoids, Health Canada requires only that they label the total concentrations of cannabidiol (CBD) and tetrahydrocannabinol (THC), combining carboxylated and decarboxylated (activated) forms. ${ }^{5}$ This variability in CBD and THC content, along with other undisclosed cannabinoids and terpenes, threatens safety and efficacy, deters 
health care providers from prescribing cannabis and prevents cannabis extracts from being placed on provincial and territorial drug formularies or covered by many private health insurance plans. ${ }^{8}$ Consequently, medical cannabis extracts are prohibitively expensive for many caregivers of children, which often leads them to turn to the recreational market or produce homemade extracts that may be unsafe. ${ }^{8}$

Research on medical cannabis use among children in Canada is hampered by inadequate national data. Health Canada reports statistics on medical cannabis use, yet these are currently not stratified by age. Health Canada also maintains a system for reporting adverse events associated with cannabis products on its Canada Vigilance website. ${ }^{9}$ Licensed cannabis producers are required to report serious adverse events associated with the use of their products, but it is not mandatory for health care providers to do so. As patients are likely to report adverse events to their health care providers or seek medical attention when a serious adverse event occurs, these may not be reported to Health Canada. Having national data on indications for use and adverse events, as well as the types of medical cannabis products and doses used in children would be invaluable.

Effectiveness research is also hampered by current regulation of cannabis production, which has resulted in the use of medical cannabis products for children rapidly outpacing the knowledge base informed from clinical trials. The production, labelling and distribution of medical and recreational cannabis follow the Health Canada's Good Production Practices (GPP), conferring confidence in their quality. ${ }^{5}$ In contrast, Health Canada's Good Manufacturing Practices (GMP) for pharmaceutical and natural health products would require more stringent documentation and additional testing to quantify THC and CBD concentrations. Recent changes made by Health Canada require cannabis products used in clinical trials to have both GMP certification and an investigator's brochure. ${ }^{10}$ Most licensed cannabis producers have neither the resources nor the expertise to perform the preclinical research required to produce an investigator's brochure on their products, which substantially limits the availability of products that can be used in clinical trials. Furthermore, the high cost of conducting clinical trials, combined with a lack of funding opportunities independent of industry, hamper good research. To address the gap in funding, research partnerships are being formed between some of the licensed cannabis producers and Canadian academic institutions, but this raises concerns about the independence of the resultant research.

In addition to the lack of high-quality research - specifically, evidence regarding the potential long-term neurodevelopmental effects of cannabis exposure in children - insufficient education for health professionals on the indications, efficacy, dosage and safety of medical cannabis products contributes to their reluctance to authorize its use in children. ${ }^{11}$ Furthermore, regulatory discrepancies between each province's and territory's physician regulators adds to health care provider uncertainty about the appropriateness of authorizing medical cannabis to children.

Current processes and regulations could be improved in several ways to better support the safe use of cannabinoids in children.
Physician authorization forms for medical cannabis should allow daily dose to be expressed as milligrams per day of the desired cannabinoid, together with the desired ratio of cannabinoids expressed in milligrams per milliliter (e.g., 1:20 THC:CBD). To ensure patients have an uninterrupted supply of their medical cannabis, a range of concentrations within the ratio could be provided (e.g., 0.5-1:18-22 THC:CBD). Furthermore, authorization forms should be revised to allow for more than 1 product for the same patient.

Licensed cannabis producers should be required to clearly display the concentrations (in $\mathrm{mg} / \mathrm{mL}$ ) of $\mathrm{THC}$, followed by the other most prominent cannabinoid, on product labels. Labels should also include (in smaller font) the concentrations of the carboxylated and decarboxylated forms of primary and other cannabinoids with a concentration greater than $1 \mathrm{mg} / \mathrm{mL}$. Such consistency in labelling will help address the concerns of caregivers and physicians regarding the potential psychoactive and long-term developmental effects of THC in children.

Although it is unrealistic to require licensed producers to use a single, standardized extraction method, they could be required to make the extraction technique used for a given product clear, as well as the source of the cannabis plant material. Several of the major licensed producers have already taken the step of preparing products to GMP standards, and this should be required of all medical cannabis products sold in Canada. Although transitioning from GPP to GMP certification may be financially challenging for providers, which could lead to increased prices of medical cannabis products, it will improve research opportunities. ${ }^{12}$ Requiring GMP certification for medical cannabis products could, however, result in a 2-tier regulatory system (with GPP and GMP certification required for recreational and medical cannabis products, respectively), and some producers may elect to exit the medical cannabis market. We suggest that, to ensure adequate supply of GMP-certified products and to provide sufficient support for pediatric clinical trials, government incentives could be offered (e.g., patents and market exclusivity, like those provided to traditional pharmaceutical companies).

Community pharmacies could be allowed to dispense and compound medical cannabis products, as most already have the necessary infrastructure and supply chains in place for ordering and storing controlled substances. As pharmacists are trained to assess drug-drug interactions and adverse effects, we support the Canadian Pharmacist Association position statement on medical cannabis, which states that pharmacists are best suited to advise patients and oversee the safe storage and dispensing of medical cannabis. ${ }^{13}$

Health Canada should stratify data on medical cannabis use by age and formulation and mandate the reporting of all serious adverse effects associated with medical cannabis, including by pharmacists. Reporting could be through the Canada Vigilance Program, in conjunction with the existing Canadian Paediatric Surveillance Program. Any reporting system should be widely accessible (i.e., by computer or phone app) and be quick and easy to use.

Lastly, a mechanism for adequate research funding, independent of industry, is required. Successfully established national 
research infrastructure is already in place with organizations such as the Canadian Childhood Cannabinoid Clinical Trials (C4T) Consortium (www.C4Trials.org), the Canadian Consortium for the Investigations of Cannabinoids and the Cannabinoid Research Initiative of Saskatchewan. These bodies are equipped to conduct high-quality, multicentre pediatric medical cannabis research in Canada. If adequate funding were made available, Canada would be well positioned to contribute greatly to the evidence base supporting the safe and effective use of medical cannabis for children whose treatment needs are otherwise inadequately met. Privatepublic partnerships can play an important part in ensuring research funding. For instance, a partnership between the Jim Pattison Children's Hospital Foundation, the Children's Hospital Foundation of Manitoba, along with Saskatchewan Health Research Foundation and Research Manitoba is being developed to provide a mechanism for licensed producers to donate nondirected funds dedicated to pediatric cannabis research. Once established, researchers will be able to apply for funding using the peer-review processes of the Saskatchewan Health Research Foundation and Research Manitoba. Intergovernmental coordination to ensure earmarking of a percentage of taxation revenues from recreational cannabis sales for research (including research on pediatric cannabis use) would also foster a better evidence base.

\section{References}

1. Pawliuk C, Chau B, Rassekh SR, et al. Efficacy and safety of paediatric medicinal cannabis use: A scoping review. Paediatr Child Health 2020;26:228-33.

2. Aran A, Cassuto H, Lubotzky A, et al. Brief report: cannabidiol-rich cannabis in children with autism spectrum disorder and severe behavioral problems-a retrospective feasibility study. J Autism Dev Disord 2019;49:1284-8.

3. An Act respecting cannabis and to amend the Controlled Drugs and Substances Act, the Criminal Code and other acts. 42nd Parliament, 1st sess, 2018 June 21. Available: https://www.parl.ca/DocumentViewer/en/42-1/bill/c-45/royal -assent (accessed 2021 Sept. 25).
4. Cannabis for medical purposes under the Cannabis Act: information and improvements. Ottawa: Health Canada; modified 2021 May 19. Available: https://www.canada.ca/en/health-canada/services/drugs-medication/cannabis /medical-use-cannabis.html (accessed 2021 Sept. 25).

5. Guidance document: Good production practices guide for cannabis. Ottawa: Health Canada; modified 2019 Dec. 4. Available: https://www.canada.ca/en/ health-canada/services/cannabis-regulations-licensed-producers/good-production -practices-guide/guidance-document.html (accessed 2021 Sept. 25).

6. Market data under the Access to Cannabis for medical Purposes Regulations. Ottawa: Health Canada; modified 2019 Aug. 29. Available: https://www.canada .ca/en/health-canada/services/drugs-medication/cannabis/licensed-producers /market-data.html (accessed 2021 Sept. 25).

7. Hazekamp A. The trouble with CBD oil. Med Cannabis Cannabinoids 2018;1: 65-72.

8. Elliott J, DeJean D, Potter BK, et al. Barriers in accessing medical cannabis for children with drug-resistant epilepsy in Canada: a qualitative study. Epilepsy Behav 2020;111:107120.

9. Cannabis recalls, adverse reactions and reporting: report side effects from cannabis products. Ottawa: Health Canada; modified 2020 Dec. 14. Available: https://www.canada.ca/en/health-canada/services/drugs-medication/cannabis /recalls-adverse-reactions-reporting/report-side-effects-cannabis-products.html (accessed 2021 Sept. 25).

10. Notice to stake holders: clarification of requirements under the Food and Drug Regulations when conducting clinical research with cannabis. Ottawa: Health Canada; modified 2021 May 31. Available: https://www.canada.ca/en/health -canada/services/drugs-health-products/drug-products/announcements/notice -clarification-requirements-conducting-clinical-research-cannabis.html (accessed 2021 Sept. 25)

11. Elliott J, DeJean D, Potter BK, et al. Neurologist's perspectives on medical cannabis for pediatric drug-resistant epilepsy in Canada: a qualitative interview study. Seizure 2020;78:118-26.

12. Mutual recognition agreement between Canada and the European Union Ottawa: health Canada; modified 2021 May 31. Available: https://www.canada. ca/en/health-canada/services/drugs-health-products/compliance-enforcement /international/mutual-recognition-agreements/updates/mutual-recognition -agreement-canada-european-community.html (accessed 2021 Sept. 25).

13. Medical cannabis. Ottawa: Canadian Pharmacists Association. Available: https://www.pharmacists.ca/advocacy/medical-cannabis/ (accessed 2021 Sept. 25).
Competing interests: Richard Huntsman and Lauren Kelly are cochairs of the Health Canada scientific advisory committee on health products containing cannabis, whose opinion is not reflected or guaranteed within. Lauren Kelly holds a Mitacs Accelerate award in partnership with Canopy Growth, unrelated to this manuscript. Juan Pablo Appendino reports honoraria from Pendopharm, Sunovion and UCB, as well as board or committee membership with the Canadian League Against Epilepsy, the Canadian Society of Clinical Neurophysiologists, the Canadian Neurological Sciences Federation and the Iberoamerican Academy of Pediatric Neurology. Richard Bélanger is on the cannabis committee of the Canadian Paediatric Society. Bruce Crooks reports participation on the data safety monitoring board of the ReRAD study, as well as membership with the Nova Scotia chapter advisory board and medical advisory committee of Make a Wish Foundation Canada. Evan Lewis has an unpaid position as medical advisor to the JMCC Canada Corp., and also reports honoraria from Spectrum Therapeutics. Alexander Repetski has an unpaid advisory position with Strainprint. Michael Rieder is a member of the drug safety monitoring board for a study exploring the use of medical cannabis for headache in children and is the principal author of the Canadian Paediatric Society's statement on medical cannabis for children. Regis Vaillancourt reports consulting fees from Harvest Medicine. No funding was received to author this manuscript. No other competing interests were declared.
This article has been peer reviewed.

Affiliations: Division of Pediatric Neurology (Huntsman), Department of Pediatrics, and Cannabinoid Research Initiative of Saskatchewan (Huntsman, Alcorn, Szafron, Shackelford), University of Saskatchewan, Saskatoon, Sask.; Canadian Childhood Cannabinoid Clinical Trial (C4T) Consortium (Kelly, Crooks, Finkelstein, Gilpin, Oberlander, Rassekh, Repetski, Rieder, Vaillancourt); George and Fay Yee Centre for Health Care Innovation (Kelly), Children's Hospital Research Institute of Manitoba, Department of Pediatrics \& Child Health, University of Manitoba, Winnipeg, Man.; College of Pharmacy and Nutrition (Alcorn), University of Saskatchewan, Saskatoon, Sask.; Division of Pediatric Neurology (Appendino, Jacobs), Department of Pediatrics, and Alberta Children's Hospital Research Institute (Appendino, Jacobs), University of Calgary, Calgary, Alta.; Départment de pédiatrie (Bélanger), Faculté de médecine, Université Laval, Québec, Que.; Canadian Paediatric Society (Bélanger, Moore-Hepburn, 't Jong), Ottawa, Ont.; Division of Paediatric Haematology/Oncology (Crooks), Department of Pediatrics, Dalhousie University, Halifax, NS; Divisions of Emergency Medicine and Clinical Pharmacology and Toxicology (Finkelstein), Department of Pediatrics, University of Toronto, Toronto, Ont.; The Rosalind and Morris Goodman Family Pediatric Formulations Centre of the Sainte-Justine University Hospital Centre (Gilpin, Litalien), Montréal, Que.; Neurology Centre of Toronto (Lewis); Division of Pediatric Neurology (Lewis), Department of 
Pediatrics, University of Toronto, Toronto, Ont.; Départment de pédiatrie (Litalien), Faculté de médecine, Université de Montréal, Montréal, Que.; Division of Paediatric Medicine (Moore-Hepburn), Department of Paediatrics, University of Toronto, Toronto, Ont.; Department of Pediatrics and School of Population and Public Health (Oberlander), and Division of Pediatric Hematology/Oncology/BMT (Rassekh), Department of Pediatrics, University of British Columbia, Vancouver, BC; Division of Pediatric Pharmacology (Rieder), Department of Pediatrics, University of Western Ontario, London, Ont.; Amarimed of Colorado (Shackelford), Denver, Colorado; Division of Palliative Care (Siden), Department of Pediatrics, University of British Columbia; Canuck Place (Siden), Children's Hospice, Vancouver, BC; School of Public Health (Szafron), University of Saskatchewan, Saskatoon, Sask.; Departments of Pediatrics and Pharmacology ('t Jong), Max Rady College of Medicine, University of Manitoba, Winnipeg, Man.; Children's Hospital of Eastern Ontario (Vaillancourt), Ottawa, Ont.

Contributors: All of the authors contributed to the conception and design of the work, drafted the manuscript, revised it critically for important intellectual content, gave final approval of the version to be published and agreed to be accountable for all aspects of the work.
Content licence: This is an Open Access article distributed in accordance with the terms of the Creative Commons Attribution (CC BY-NC-ND 4.0) licence, which permits use, distribution and reproduction in any medium, provided that the original publication is properly cited, the use is noncommercial (i.e., research or educational use), and no modifications or adaptations are made. See: https://creativecommons.org/licenses/ by-nc-nd/4.0/

Acknowledgements: The authors would like to acknowledge the contributions of the following members of the Cannabinoid Research Initiative of Saskatchewan and Canadian Childhood Cannabinoid Clinical Trial (C4T) Consortium who provided their expertise in editing the manuscript: Drs. Blair Seifert and Declan Quinn, as well as Simona Meier and Scott Corley. They would also like to express their gratitude to the Maternal Infant Child and Youth Research Network and their scientific director (Dr. Thierry Lacaze-Masmonteil) for their ongoing support of the C4T Consortium. This support allowed for a mechanism for the authors to collaborate in a national framework.

Correspondence to: Richard Huntsman, dr.huntsman@usask.ca 